\title{
Chapter 8 Assessing Future Resilience, Equity, and Sustainability in Scenario Planning
}

\author{
Marta Berbés-Blázquez, Nancy B. Grimm, Elizabeth M. Cook, \\ David M. Iwaniec, Tischa A. Muñoz-Erickson, Vivian Hobbins, \\ and Darin Wahl
}

\begin{abstract}
In the absence of strong international agreements, many municipal governments are leading efforts to build resilience to climate change in general and to extreme weather events in particular. However, it is notoriously difficult to guide and activate processes of change in complex adaptive systems such as cities. Participatory scenario planning with city professionals and members of civil society provides an opportunity to coproduce positive visions of the future. Yet, not all visions are created equal. In this chapter, we introduce the Resilience, Equity, and Sustainability Qualitative (RESQ) assessment tool that we have applied to compare positive scenario visions for cities in the USA and Latin America. We use the tool to examine the visions of the two desert cities in the Urban Resilience to Extreme Events Sustainability Research Network (UREx SRN), which are Hermosillo (Mexico) and Phoenix (United States).
\end{abstract}

\footnotetext{
M. Berbés-Blázquez ( $\varangle)$

School for the Future of Innovation in Society, Arizona State University, Arizona, USA

e-mail: mberbes@asu.edu
}

\section{N. B. Grimm}

School of Life Sciences, Arizona State University, Arizona, USA

Julie Ann Wrigley Global Institute of Sustainability, Arizona State University, Tempe, AZ, USA

E. M. Cook

Environmental Science, Barnard College, New York, NY, USA

D. M. Iwaniec

Andrew Young School of Policy Studies, Urban Studies Institute, Georgia State University, Georgia, USA

\section{T. A. Muñoz-Erickson}

USDA Forest Service, International Institute of Tropical Forestry, Río Piedras, PR, USA

\author{
V. Hobbins \\ Instituto Tecnológico de Sonora, Sonora, Mexico, USA \\ D. Wahl \\ Lund University Centre for Sustainability Studies, Lund, Sweden
}

(C) This is a U.S. government work and not under copyright protection in the U.S.; 
Keywords Extreme weather events - RESQ assessment - Climate resilience • Sustainability $\cdot$ Future visions

Scenario planning is a tool to inform management actions in situations of deep uncertainty. It is therefore not surprising that in recent decades, scenario approaches have been used to explore complex issues such as climate change adaptation, urbanization, or biodiversity conservation. The scenario process produces a set of alternative futures of a place, or a situation, that allow comparisons between the outcomes of adopting different policy decisions. In doing so, scenarios not only offer a way of representing complexity but also a means for comparison. The ability to explicitly compare the positive and negative outcomes of competing policy options makes scenarios a valuable instrument to support and guide decision-making.

There are different ways of assessing and exploring the desirability of alternative scenario visions. Traditionally, scenario work has relied on modeling outputs as a means of comparison. Models can show quantitative differences in key variables of the system, such as water use or land use, which are easy to grasp and relate directly to policy goals. At the same time, models have limitations. The most obvious is that modeling is restricted to the aspects of the future visions that have a quantifiable, biophysical expression. Therefore, intangible qualities that might be highly desirable, such as creating a sense of place or valuing the history of a neighborhood, cannot be captured by models. This means that one of the main strengths of the scenario technique, which is the production of rich, textured, nuanced depictions of the future based on the integration of different ways of knowing, is left out of the evaluative part of the exercise because of the lack of a physical approximation. In this chapter, we introduce the Resilience, Equity, and Sustainability Qualitative (RESQ) assessment tool that we have applied to compare coproduced scenarios for cities in the USA and Latin America. We use as examples two heat and drought scenarios that were developed in the Sonoran Desert cities of Hermosillo (Mexico) and Phoenix (USA). This pair of scenarios illustrate how two cities facing the same climate challenge might envision their future differently. In our work, the RESQ assessment is complementary to other comparative analyses, including models for future land use/land change (see Chap. 7), rich narratives, and visual renderings of the future. Beyond evaluation, having a variety of synthetic outputs from scenario planning offers a range of entry points with which to engage a wider audience. The chapter is structured as follows: we first provide definitions for the key concepts of resilience, equity, and sustainability before we delve into the case studies for Hermosillo and Phoenix. We then reflect on the potential of the RESQ assessment as a heuristic tool for social learning, and briefly explore its strengths and limitations. 


\subsection{An Instrument for Assessment}

\subsubsection{Defining Resilience, Equity, Sustainability}

A broad goal of the UREx SRN project is to create positive urban visions to assist cities in building resilience to extreme events, advancing sustainability, and ensuring equity. All of these terms are used widely and inconsistently in the literature. Hence, in this section, we present our definitions for resilience, sustainability, and equity and explain our approach to their assessment.

\subsubsection{Resilience}

Resilience, as used in the context of social-ecological-technological systems, refers to the capacity of a complex adaptive system to absorb disturbance while remaining within a given domain of attraction that is defined by structure, function, identity, and feedbacks (Carpenter et al. 2001). Climate resilience, which is relevant to our work, adds specificity to Carpenter's definition and is understood as the ability of communities to persist, adapt, and recover in the face of climate stresses and shocks (Tanner et al. 2009; Wardekker et al. 2010). Increasingly, there have been calls to provide resilience metrics to help guide management decisions (Quinlan et al. 2015). While it is possible to identify concrete metrics for the resilience of wellstudied systems like lakes — where nutrient loading is the key variable that determines whether the lake is in its eutrophic or oligotrophic state-it is a great deal more difficult to identify and measure metrics for complex and contested systems like cities (Meerow et al. 2016). Doing so is further complicated by the fact that our visions represent future states, and hence, indicators that might be relevant today might not be relevant in the future, nor would they capture the idiosyncrasies of cities around the world. Hence, our assessment focuses on the identification and evaluation of general mechanisms that enhance resilience and are applicable to a variety of complex systems. Our list of principles is based on Walker and Salt (2006), Chapin et al. (2009), and Biggs et al. (2012), and is as follows:

- Diversity. Actions that increase or maintain diversity increase the resilience of a social-ecological-technological system. Diversity can mean increasing variety (how many distinct elements there are), balance (how many of each distinct element there are), or disparity (the extent to which elements are distinct from one another). Strategies to increase diversity can be ecological, such as introducing pollinator gardens in front lawns; social, such as opening decision-making processes to a broader set of actors; and technical, such as amplifying the kinds of energy sources that make up a city's energy portfolio.

- Functional redundancy. Resilience is enhanced by mechanisms that build redundancy, that is, by having components within the system that fulfill similar or overlapping functions that will allow the system to continue to operate even if a 
specific component fails. For instance, natural and mechanical infrastructures can be combined to create shade in public spaces. Both provide cooling benefits, but they are affected by extreme events differently; for example, a drought can kill vegetation but will not affect shade infrastructure.

- Connectivity. Managing the links between different components of a system is important for resilience. Increasing connectivity is necessary at times, as when people come together after a disaster; at other times, decreasing connectivity is needed; for example, quarantining a diseased population.

- Slow variables. The resilience of a system is largely dependent on critical variables that control its internal dynamics and generally change at a gradual pace (see Walker et al. 2012). For example, land-use zoning determines density in cities, which is a slow variable that in turn may promote or inhibit services such as mass transit, social programs, or green belts.

- Feedbacks. The resilience of a system depends on reinforcing or dampening responses in reaction to an initial stimulus (positive or negative feedback loops), which may occur at a later time or in a distant location. Sometimes feedbacks are set up intentionally; for example, using pricing mechanisms to manage water usage. Other times, feedbacks are manifestations of unintended consequences; for example, adding road lanes to reduce gridlock usually has the opposite effect.

- Complex system lens. Adopting a holistic perspective that seeks to understand adaptive behavior builds resilience when dealing with uncertainty. A systems lens considers not only the social, ecological, and technological elements of the system but also their interactions across scales. Extreme events often demonstrate the interconnectedness of systems. The aftermath of Hurricane Maria in Puerto Rico in 2017 exemplified the degree to which vulnerability is a product of socialecological-technological flows of information, financial transactions, people, and materials - all of which need to be considered simultaneously and across scales (Eakin et al. 2018).

- Learning. Learning is a key in situations of uncertainty and can take many forms, from awareness-raising campaigns to changes in the educational curriculum. We pay special attention to processes leading to double-loop learning (sensu Argyris 1999) and social learning (Reed et al. 2010), which have the potential to transform societal values.

- Adaptive management. The practice of adaptive environmental management is used under conditions of uncertainty. It is often dubbed "learning by doing" because it intends to improve our understanding of how a system works through management policies that are taken to be hypotheses. Therefore, adaptive management encourages experimentation, monitoring, and iterative decision-making.

- Participation. Broadening participation means that decisions are made based on a more complete understanding of the issue built on a variety of perspectives. This leads to better-informed decisions, with more buy-in and empowerment of participants.

- Polycentric governance. In polycentric governance, there are several nodes with decision-making capacity that act with some degree of autonomy from one another, and there is usually an effort to match the governing authority with the 
scale of the problem. For example, in some jurisdictions, there may be water boards that make decisions for a watershed, working in conjunction with one another but separate from other branches of government.

\subsubsection{Sustainability and Equity}

The term sustainability was first coined in 1972 by the Club of Rome to seek a balance between satisfying the needs of people and respecting the biophysical limits of the planet's ecosystems. Thus, sustainability sought to temper the push for economic development with a long term, ecological perspective. It was understood that sustainability was critical to guide development in the Global South. Fifteen years later, the World Commission on Environment and Development published Our Common Future, where they defined sustainable development as "meet[ing] the needs of the present without compromising the ability of future generations to meet their own needs" (Brundtland 1987, p. 43). Hence, the Brundtland Report made intra and intergenerational equity considerations more central to the definition. The Brundtland Report also established the idea of sustainability in the international policy arena. Over the years, global initiatives have sought to operationalize sustainability into the development agendas of individual countries. One such initiative was the Sustainable Development Goals (SDGs), which were adopted at the 2012 United Nations Conference on Sustainable Development in Rio de Janeiro. The SDGs replaced the earlier iteration of global targets for sustainable development, the Millennium Development Goals (2000). Compared with the Millennium Development Goals, the SDGs are more comprehensive in scope, including goals like job creation, peace building, and responsible consumption; as such, the SDGs are broadly applicable to both rich and poor nations. The 17 SDGs are as follows:

- Goal 1. End poverty in all its forms everywhere.

- Goal 2. End hunger, achieve food security and improved nutrition, and promote sustainable agriculture.

- Goal 3. Ensure healthy lives and promote well-being for all at all ages.

- Goal 4. Ensure inclusive and equitable quality education and promote life-long learning opportunities for all.

- Goal 5. Achieve gender equality and empower all women and girls.

- Goal 6. Ensure availability and sustainable management of water and sanitation for all.

- Goal 7. Ensure access to affordable, reliable, sustainable, and modern energy for all.

- Goal 8. Promote sustained, inclusive and sustainable economic growth, full and productive employment and decent work for all.

- Goal 9. Build resilient infrastructure, promote inclusive and sustainable industrialization, and foster innovation.

- Goal 10. Reduce inequality within and among countries.

- Goal 11. Make cities and human settlements inclusive, safe, resilient and sustainable. 
- Goal 12. Ensure sustainable consumption and production patterns.

- Goal 13. Take urgent action to combat climate change and its impacts.

- Goal 14. Conserve and sustainably use the oceans, seas and marine resources for sustainable development.

- Goal 15. Protect, restore and promote sustainable use of terrestrial ecosystems, sustainably manage forests, combat desertification, and halt and reverse land degradation and halt biodiversity loss.

- Goal 16. Promote peaceful and inclusive societies for sustainable development, provide access to justice for all and build effective, accountable and inclusive institutions at all levels.

- Goal 17. Strengthen the means of implementation and revitalize the global partnership for sustainable development.

We use the SDGs to assess equity and sustainability in our scenario visions. However, we have modified this list in two ways in our assessment: First, we consider the subgoals associated with SDG11, since it pertains to cities. Hence, we are assessing explicitly the following subgoals: (1) providing safe and affordable housing; (2) having access to safe, affordable, and sustainable transportation; (3) participatory governance for urban planning; (4) protecting the world's cultural and natural heritage; (5) reducing the adverse environmental impact of cities (e.g., cutting atmospheric pollution); (6) access to green and public spaces; (7) considering multiscalar relations between urban, per-urban, and rural areas; and (8) building sustainable and resilient buildings with local materials. Second, we have excluded SDG 13 (taking action on climate change) because it is repetitive, as well as SDG 17 (revitalizing the global partnership for sustainable development) because it is not applicable at the scale of our city scenarios.

\subsubsection{Qualitative Assessment-How It Works}

An important part of the RESQ tool is to maintain a systems view of the future vision. Thus, the assessment begins by identifying the three to five defining characteristics of the scenario that capture its identity. These constitute the vision's key components sensu Holling's (2001) "rule of hand," which states that even very complex systems can be understood by identifying three to five key interacting components that organize all the rest. Thus, the rule of hand organizes the variables of the system in a hierarchy to reduce the amount of complexity and avoid being bogged down by details. This is especially useful when dealing with data from scenario processes that produce rich and nuanced depictions of the future. In our work, we use the rule of hand to characterize the essence of a vision co-developed in scenario workshops, where participants construct visions through guided activities that include brainstorming, goal-setting, mapping exercises, prioritization, and story-telling (see Iwaniec et al. 2020). The actual process for determining the key components is 

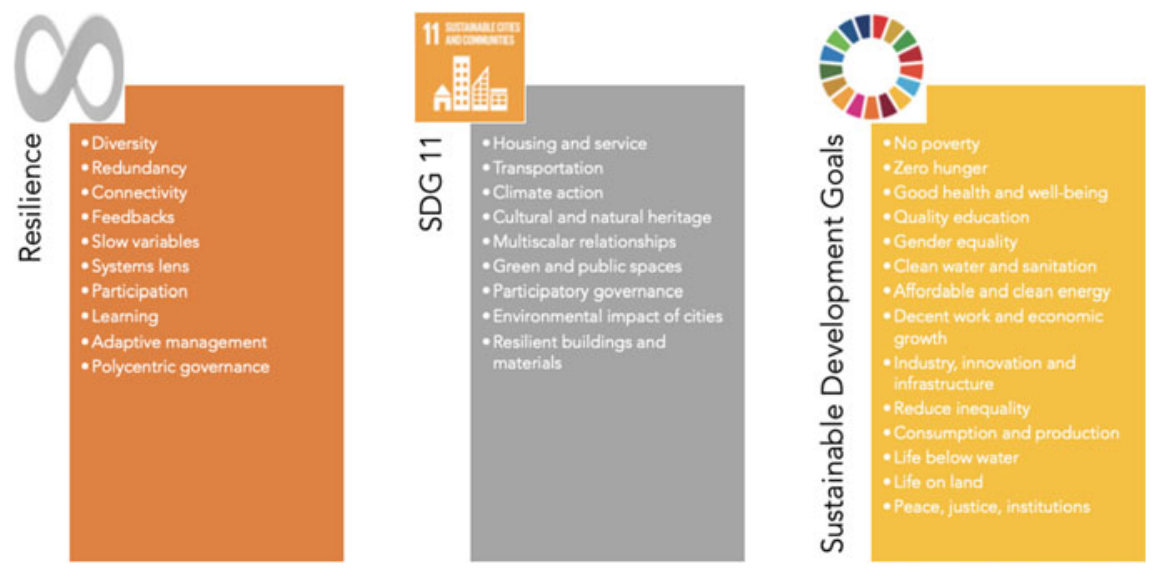

Fig. 8.1 Principles associated with resilience, equity, and sustainability used in our qualitative assessment

similar to qualitative coding, in which underlying themes are identified by carefully studying data from the workshops, including notes, maps, and narratives. For example, increasing green infrastructure might emerge as a key component of a future vision, and subsumed within it might be several more detailed strategies, such as building bioswales, providing subsidies for green roofs in commercial buildings, targeting educational campaigns for school children, and updating the building code for new construction to require green features. In order to ensure consistency in our work, at least three researchers reviewed and agreed on the identification of key components.

After the key components are identified, they are assessed against the resilience principles and the SDGs goals identified earlier (Fig. 8.1) using a Likert scale from 0 (absent) to 4 (present). Again, this assessment is qualitative and considers all of the outputs from the workshop activities. In the green infrastructure example, the key component of increasing green infrastructure would get high scores on principles related to greening the city (SDG 11.7) and lower scores on principles related to polycentric governance. Because future visions are complex, the key components that make up a vision may have very different foci that build different aspects of resilience, equity, and/or sustainability. Hence, we use an average of the scores assessed for each key component when presenting our results. Each key component was scored by two researchers separately and reviewed by a third.

\subsection{Comparing Drought and Heat Scenarios}

Cities around the world will face more intense and frequent climate-related extreme events in the future. In this section, we consider how two arid-land cities envision 
coping with or adapting to more extreme heat, longer drought periods, and water shortages. Both Hermosillo and Phoenix are situated in the Sonoran Desert, approximately $500 \mathrm{~km}$ apart as the crow flies. Hermosillo is the capital city of the state of Sonora, with a population just shy of one million people. Phoenix is the capital of the state of Arizona, with a metro population of nearly 5 million people. Climate models for the Sonoran Desert region predict an increase in temperature and a decline in overall precipitation, but with particular regard to winter-spring precipitation that generates most of the water supply, as well as to the decline of snowpack at higher elevations that supports flow in major water-supply rivers (Wuebbles et al. 2017). This combination of higher temperatures with lower winter precipitation and snowpack means that droughts will last longer and be more frequent. It is clear from this projection that water security is a pressing issue for both municipalities.

The two visions showcased as examples in this chapter were created following the scenario method outlined in Chapter 6 (see also Iwaniec et al. 2020). In this form of scenario planning, workshops are used to convene a group of 30-40 municipal practitioners, representatives of civil society, and academics. The group is divided into thematic work tables, each with five or six participants. The themes of the work tables are decided in advance but defined broadly enough to accommodate diverse viewpoints in the workshop. The themes become scenarios, or visions, through the activities of the workshop. Typical themes of the UREx SRN scenarios explored the adaptation to extreme events, such as heat, drought, and flooding. We refer to these as adaptive scenarios. There were also transformative scenarios that considered the future of broader, usually normative, issues such as equity, transportation, or housing. Throughout the day participants worked with a facilitator on different activities designed to identify large goals and specific strategies associated with those goals, each defined in terms of time (when they will occur) and space (where they will be implemented). Although we produced five visions in Phoenix and six visions in Hermosillo, for simplicity, we are choosing to compare the adaptive scenarios that had to do with building resilience to heat and drought in each city.

\subsubsection{Identifying Key Components}

The scenario vision for Hermosillo was built around three key components, the first being aggressive water conservation measures. These measures ranged from developing wastewater treatment and reuse infrastructure, to installing rainwater harvesting devices in households, to promoting xeric landscaping on public lands. The second key component emphasized the establishment of natural areas for watersource protection and to increase green infrastructure. For example, participants envisioned reducing agricultural land use and setting aside 50,000 hectares of forest in the watershed to protect the headwaters, and creating a network of green corridors and filtration ponds to reduce the amount of flash floods. The third key component of the Hermosillo vision aimed to raise awareness and capacity to manage water use through a variety of strategies that included general education campaigns, apps to 
monitor water quality and quantity, education materials for schools, and the creation of a network of multidisciplinary experts to weigh in on water management decisions.

The Phoenix vision also had three key components. Similar to Hermosillo, the first key component emphasized drastic water conservation measures with similar strategies around water harvesting and wastewater reuse; however, in Phoenix, participants also envisioned centralized, underground water banking as a key piece of their vision to ensure the city's future water supply. The next key component for the Phoenix scenario was directed at managing urban density, thus, there was a push to limit sprawl, increase density in the city core, and reduce periurban agriculture, which is currently a large water consumer. To make up for the loss of agricultural productivity, the third key component of this vision aimed to increase urban agriculture through the proliferation of community gardens, vertical gardens of drought-tolerant plants, and the growth of farm-to-table movements.

\subsubsection{Assessing Resilience-Building Mechanisms}

The resilience assessments for the Hermosillo and Phoenix visions are shown in Fig. 8.2. The assessment for the Hermosillo vision shows that it had well-developed mechanisms for increasing redundancy, connectivity, diversity, and participation. Redundancy and diversity tend to score similarly because often, strategies that increase redundancy also increase diversity. In this case, the vision showed that participants not only identified a broad variety of strategies for reducing water consumption, but that these strategies had functional overlap. The Hermosillo vision also scored high in participation as it contained many strategies for capacity-building and public engagement; for example, involving residents in water monitoring and education campaigns for different audiences. Finally, and related to participation, the strategies that increased connectivity in the scenario were mostly social and had to do with efforts to connect and inform people about water issues.

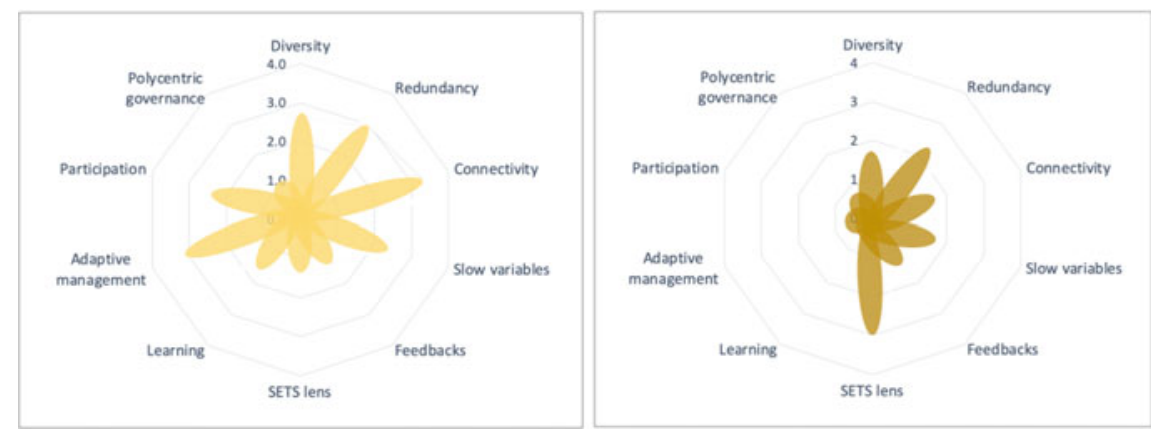

Fig. 8.2 Comparison of resilience-building mechanisms in the drought and heat scenario visions for Hermosillo (left) and Phoenix (right) 


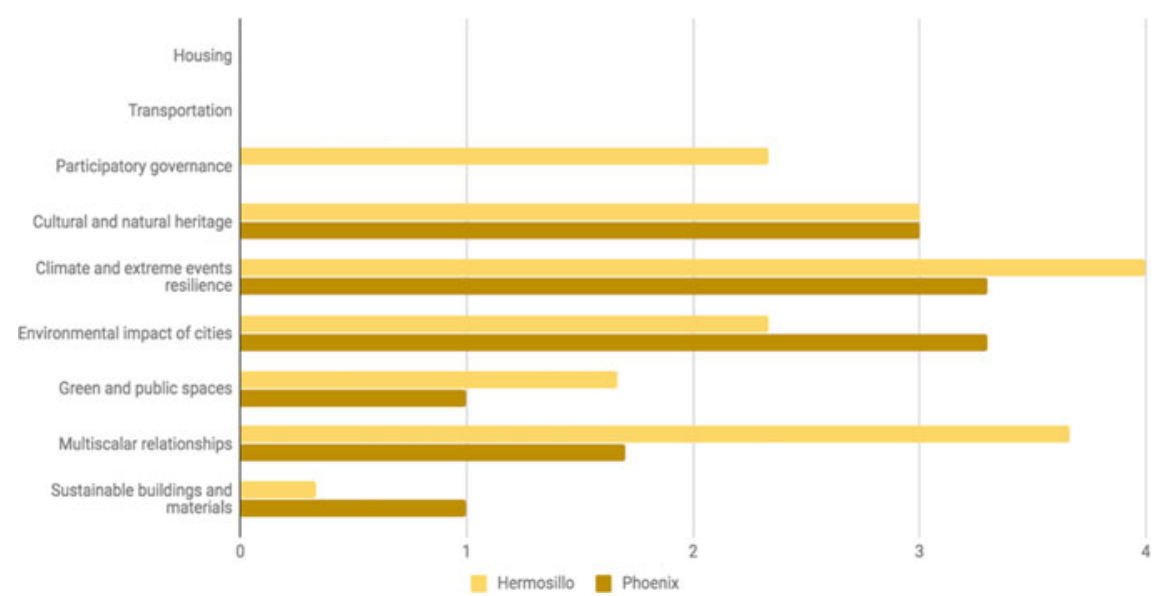

Fig. 8.3 Comparison of subgoals associated with Sustainable Development Goal 11: Sustainable Cities and Communities, in Hermosillo and Phoenix

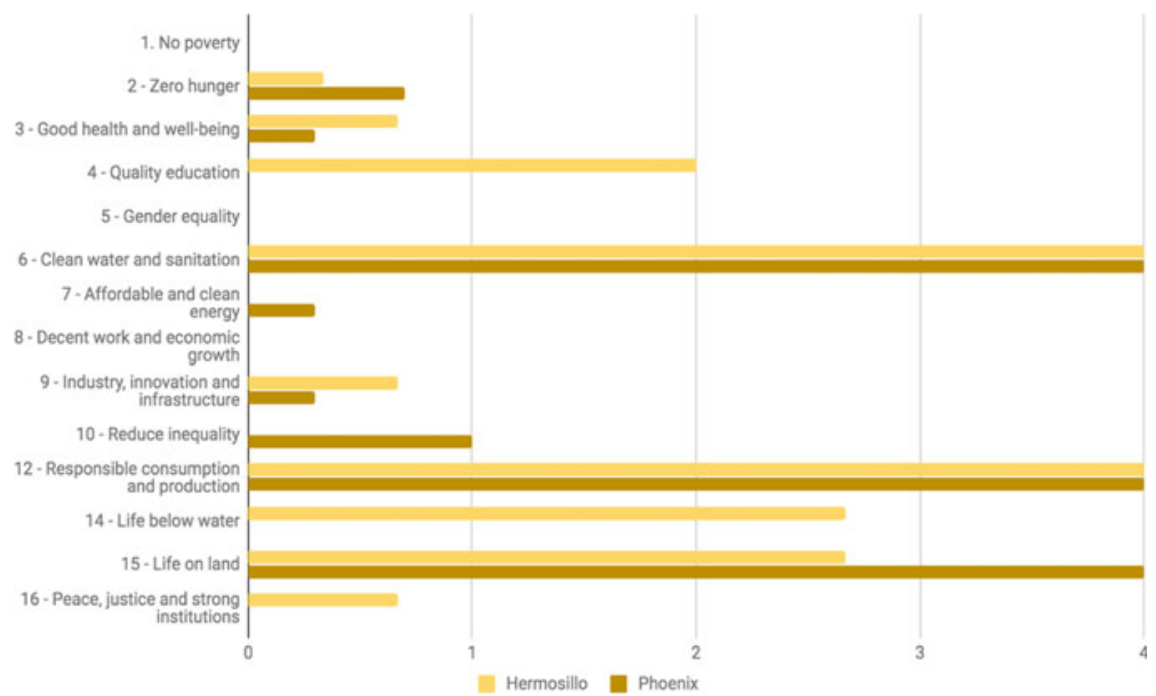

Fig. 8.4 Comparison of Sustainable Development Goals for Hermosillo and Phoenix

On the other hand, the vision of Phoenix scored highest in terms of adopting a systems lens. A systems lens means that there is evidence that participants were considering the interactions among social, ecological, and technological elements across scales. For instance, the way in which participants managed density and landuse change in the Phoenix vision showed that they were considering the links between urban and periurban regions, as well as social, ecological, and technological repercussions of reducing agriculture and increasing urban density. The Phoenix vision also 
scored high on redundancy since it had many overlapping strategies for water conservation happening at different scales, from high-efficiency plumbing in households to centralized water banking (see Fig. 8.2).

When we consider the two visions in general, we notice that both visions scored higher on the principles that are pertinent to changing parts of the system structure (i.e., increasing diversity, redundancy, and connectivity). Both visions had average scores on the principles that encourage systemic thinking (i.e., considering slow variables, feedbacks, and using systems thinking lens), and they scored lowest, particularly Phoenix, on the principles related to management and governance (i.e., practicing adaptive management, learning, participation, and polycentricity). When we compare the two assessments, we note that the drought vision for Hermosillo has more developed resilience-building mechanisms than the vision created for Phoenix, with the biggest differences being the degree of participation and the wish to implement adaptive management. This may reflect the cities' differences in the degree to which drought and water shortage are considered to be challenges today: Hermosillo has more of a history of water scarcity, including water rationing (Eakin et al. 2007), than does Phoenix.

\subsubsection{Assessing Sustainability and Equity}

The two scenarios scored low in the assessment of SDG11's subgoals and the sustainable development goals in general (Figs. 8.3 and 8.4). This likely reflects the fact that both of these visions represent adaptive scenarios, which are issue-driven scenarios, instead of transformative scenarios, which emphasize a more holistic vision for an improved city (see Chap. 6). What this means is that participants focused more narrowly on creating a vision to solve the drought issue and did not consider other aspects that make cities livable. Topics like housing, transportation, gender equity, poverty alleviation, or job creation seem to have been absent from the conversation, despite important linkages between them and drought. On the other hand, both scenarios scored high on the SDG goals that were related to water quality and quantity and the impacts of climate change.

\subsection{Discussion and Conclusion}

In sustainability science, scenarios have long been hailed as a tool for exploring the normative dimensions of alternative futures pertinent to policy-making (Swart et al. 2004; Wiek and Iwaniec 2014, Raudsepp-Hearne et al. 2019). Yet, the degree to which scenarios influence actual policy decisions remains to be seen. In terms of framing issues, scenarios have found more use during initial stages of the policy cycle than in policy design and implementation (Volkery and Ribeiro 2009). Beyond institutional barriers, one outstanding issue is that normative evaluation is inherently difficult 
because it involves assessing values and beliefs. We see the RESQ assessment as a launching point to open a dialog on these normative dimensions of the future.

The main strength of the RESQ is that it serves as a heuristic tool for comparison and reflection. For example, in some of the UREx SRN project cities, we held a subsequent workshop where we presented the RESQ assessment to the participants who created the visions and prompted them to reconsider what worked and what was missing from their ideal future. It is through this reflection that participants realize how their vision may have resulted in a wealth of diversification strategies yet had left out consideration of governance mechanisms. The RESQ is most useful when used comparatively. For example, stakeholder groups that created different visions might compare their RESQ scores and get ideas on strategies and mechanisms to adapt for their own vision. It is in this sense that the RESQ assessment supports processes of coproduction and social learning - the sustained learning that happens through continued interactions and deliberation that change people's attitudes and behaviors (Reed et al. 2010).

At the same time, decision-makers often want to see metrics that can be used to monitor progress and impacts of a policy choice. Although we have steered clear of creating an index, the RESQ assessment can be a first step toward developing more concrete indicators that are relevant to the local context. For instance, if a city vision emphasizes mechanisms to manage slow variables, there could be a number of social, ecological, and technological indicators that can be developed, such as surveying changes in people's attitudes over time, checking groundwater recharge rates, or monitoring land-use change in the city. These indicators should be developed in discussion with participants to ensure relevancy to their context.

Finally, a warning, any assessment tool that tries to capture the nature of a complex adaptive system is grappling with incommensurability (Quinlan et al. 2015). Even a qualitative assessment such as the RESQ risks oversimplification. Thus, we offer this tool as a means to aid the policy process and not as an end in itself (Stirling 1999). That is, the process of making decisions about how a society should enhance resilience, equity, and sustainability is a great deal more political and contested than the RESQ, or any other tool for assessment, suggests.

\section{References}

Argyris C (1999) On organizational learning, 2nd edn. Blackwell, Oxford

Biggs R, Schlüter M, Biggs D et al (2012) Toward principles for enhancing the resilience of ecosystem services. Annu Rev Environ Resour 37:421-448

Brundtland G (1987) Report of the World Commission on Environment and Development: Our Common Future. United Nations General Assembly. Available via https://sustainabledevelop ment.un.org/milestones/wced. Accessed 17 June 2020.

Carpenter S, Walker B, Anderies JM, Abel N (2001) From metaphor to measurement: resilience of what to what? Ecosystems 4(8):765-781

Chapin FS III, Kofinas GP, Folke C et al (2009) Principles of ecosystem stewardship: resiliencebased natural resource management in a changing world. Springer-Verlag, New York 
Eakin H, Magaña V, Smith J et al (2007) A stakeholder driven process to reduce vulnerability to climate change in Hermosillo, Sonora, Mexico. Mitigat Adapt Strateg Glob Chan 12(5):935-955

Eakin H, Muñoz-Erickson TA, Lemos MC (2018) Critical lines of action for vulnerability and resilience research and practice: lessons from the 2017 hurricane season. J Extreme Events $5(2): 1850015$

Holling CS (2001) Understanding the complexity of economic, ecological, and social systems. Ecosystems 4(5):390-405

Iwaniec DM, Cook EM, Davidson M et al (2020) The co-production of sustainable future scenarios. Landscape Urban Plann 197:103744

Meerow S, Newell JP, Stults M (2016) Defining urban resilience: a review. Landscape Urban Plann 147:38-49

Quinlan AE, Berbés-Blázquez M, Haider LJ et al (2015) Measuring and assessing resilience: broadening understanding through multiple disciplinary perspectives. J Appl Ecol 53(3):677-687

Raudsepp-Hearne C, Peterson GD, Bennett EM et al (2019) Seeds of good anthropocenes: developing sustainability scenarios for Northern Europe. Sustain Sci 15(2):605-617

Reed M, Evely AC, Cundill G et al (2010) What is social learning? Ecol Soc 15(4)

Stirling A (1999) The appraisal of sustainability: some problems and possible responses. Local Environ 4(2):111-135

Swart RJ, Raskin P, Robinson J (2004) The problem of the future: sustainability science and scenario analysis. Glob Environ Chan 14(2):137-146

Tanner T, Mitchell T, Polack E et al (2009) Urban governance for adaptation: assessing climate change resilience in ten Asian cities. Institute of Development Studies Working Papers, pp 1-47

Volkery A, Ribeiro T (2009) Scenario planning in public policy: understanding use, impacts and the role of institutional context factors. Technol Forecast Soc Chan 76(9):1198-1207

Walker B, Carpenter S, Rockstrom J et al (2012) Drivers, "slow" variables, "fast" variables, shocks, and resilience. EcolSoc 17(3)

Wardekker JA, de Jong A, Knoop JM et al (2010) Operationalising a resilience approach to adapting an urban delta to uncertain climate changes. Technol Forecast Soc Chan 77(6):987-998

WiekA ID (2014) Quality criteria for visions and visioning in sustainability science. Sustain Sci 9(4):497-512

Wuebbles DJ, Fahey DW, Hibbard KA et al (eds) (2017) Climate science special report: fourth national climate assessment, vol I. U.S, Global Change Research Program, Washington, DC

Marta Berbés-Blázquez is an Assistant Professor at the School for the Future of Innovation at Arizona State University. Her research considers the human dimensions of social-ecological transformations in rural and urban ecosystems with an emphasis on vulnerable populations. Her work is informed by resilience thinking and political ecology at a conceptual level, and it is practically oriented toward qualitative, participatory, and anticipatory research methods. Specific topics of expertise include power dynamics and access in ecosystem services, scenario planning, resource extraction, eco-health, climate change adaptation, and transformation.

Nancy B. Grimm studies the interactions between climate variation and change, human activities, and ecosystems. Her interdisciplinary urban and stream ecosystem research focuses on disturbance, resilience, and bio-geochemical processes. Dr. Grimm is Regents Professor at Arizona State University and currently co-directs the Urban Resilience to Extremes Sustainability Research Network (UREx SRN). She was president (2005-06) and is a fellow of the Ecological Society of America, as well as a fellow of the American Geophysical Union (AGU), the American Association for the Advancement of Science (AAAS), and the Society for Freshwater Science. She is an elected member (2019) of the US National Academy of Sciences. 
Elizabeth M. Cook is an Assistant Professor at Barnard College in the Department of Environmental Science. She is an urban ecosystem ecologist and her research focuses on future urban sustainability and human-environment feedbacks in urban and nearby native ecosystems. She conducts research on sustainability and resilience planning through participatory scenario development with local stakeholders. Her work seeks to understand cities as social-ecologicaltechnological systems with a comparative approach in Latin American and U.S. cities. Cook holds a Ph.D. from Arizona State University and a Bachelor of Arts from Wellesley College.

David M. Iwaniec is an Assistant Professor of Urban Sustainability at the Urban Studies Institute, Andrew Young School of Policy Studies at Georgia State University. He is a sustainability scientist researching anticipatory and systems approaches to advance urban sustainability, resilience, and justice. His work focuses on the co-development of scenarios and transition pathways for positive futures of urban transformation.

Tischa A. Muñoz-Erickson is a Research Social Scientist in the USDA Forest Service's International Institute of Tropical Forestry, in Río Piedras, Puerto Rico. She studies urban sustainability governance, including the policy networks, knowledge systems, anticipatory capacities, and strategies to advance sustainability, resilience, and equity. She is also actively involved in transdisciplinary platforms to facilitate the co-production of futures and transition pathways in the US and Latin American cities. Muñoz-Erickson leads the International Urban Field Station and the San Juan ULTRA and is also Co-PI of the National Science Foundation Urban Resilience to Extreme Events Sustainability Research Network (UREx SRN) and the SETS Convergence project.

Vivian Hobbins is an interdisciplinary scientist working as an Adjunct Faculty in the College of Science for Grand Canyon University. She graduated with honors from Sonora Technological Institute (ITSON) with a BS in Civil Engineering. She also completed an MS in Natural Resources and her Ph.D. in Ecohydrology at ITSON. Her collaborative research with the Urban Resilience to Extremes Sustainability Research Network focused mainly on data acquisition and modeling of the effects of flooding and drought in urban centers in the Americas. Vivian has experience collaborating with various stakeholders in US and Latin American cities to assess the vulnerability of communities and infrastructure to extreme climate events and to develop solutions to build climate resilience. She is now dedicating her life to teaching the next generation of environmental scientists and engineers, as well as empowering instructors to transfer their knowledge and expertise effectively across generations.

Darin Wahl is a Ph.D. candidate at the Lund University Centre for Sustainability Studies. His current work focuses on sustainability innovations in natural resource systems through Urban Living Labs. His research interests include urban resilience to climate change impacts and sense of place in the context of sustainability transitions and transformations. Darin works through interdisciplinary and transdisciplinary processes aiming to learn with others to develop solutions to complex sustainability issues. 
Open Access This chapter is licensed under the terms of the Creative Commons Attribution 4.0 International License (http://creativecommons.org/licenses/by/4.0/), which permits use, sharing, adaptation, distribution and reproduction in any medium or format, as long as you give appropriate credit to the original author(s) and the source, provide a link to the Creative Commons license and indicate if changes were made.

The images or other third party material in this chapter are included in the chapter's Creative Commons license, unless indicated otherwise in a credit line to the material. If material is not included in the chapter's Creative Commons license and your intended use is not permitted by statutory regulation or exceeds the permitted use, you will need to obtain permission directly from the copyright holder.

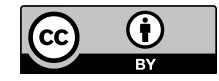

